\title{
Optimization and Electrochemical Study on the Control of Mild Steel Corrosion in Hydrochloric Acid Solution with Bitter Kola Leaf Extract as Inhibitor
}

\author{
V.C. Anadebe ${ }^{\mathrm{a}, *} \mathbb{D D}^{\S}$, O.D. Onukwuli ${ }^{\mathrm{b}}$, M. Omotioma ${ }^{c}$ and N.A Okafor ${ }^{\mathrm{d}}$ \\ ${ }^{a}$ Department of Chemical Engineering, Federal University Ndufu Alike Ikwo, Ebonyi State, Nigeria. \\ ${ }^{b}$ Department of Chemical Engineering, Nnamdi Azikwe University Awka, Anambra state, Nigeria. \\ ${ }^{c}$ Department of Chemical Engineering, Enugu State University of Sci \& Tech, Enugu State, Nigeria. \\ ${ }^{d}$ Department of Chemical Engineering, Chukwuemeka Odumegwu Ojukwu University, Nigeria.
}

Received 25 January 2018, revised 24 May 2018, accepted 25 May 2018.

\begin{abstract}
Response surface methodology was applied to predict the optimum control of mild steel corrosion in acid medium with bitter kola leaf extract as inhibitor. The experiment was carried out to investigate the mutual interactions between the considered independent variables and the expected responses. Thermometric, gravimetric, potentiodynamics polarization and electrochemical impedance spectroscopy were used in the corrosion inhibition study. As a supplementary technique, infrared spectroscopy was used to analyze the pure extract and corrosion products and it was observed that some peaks shifted while some disappeared. Inhibition efficiencies of $88.24 \%, 86.81 \%, 90 \%, 89.5 \%$ and $85.3 \%$ were obtained from optimization, thermometric, gravimetric, potentiodynamics polarization and electrochemical impedance spectroscopic techniques, respectively. The bitter kola leaf extract behaved as a mixed-mode inhibitor. Application of response surface methodology in this study was found to be good in predicting the optimum range for controlling of metal corrosion thereby reducing the number of experimental runs.
\end{abstract}

KEYWORDS

Acid, bitter kola leaf, Fourier transform infrared, mild steel, electrochemical impedance spectroscopy, potentio dynamics polarization.

\section{Introduction}

Mild steel is a useful metal in engineering. Its usefulness is endangered by corrosion phenomenon. Corrosion is simply explained as the disintegration of metal by a reaction with its environment and is generally faster when the average atmospheric temperature is high. Some metals corrode, while many of other metals (for example, silver, gold and platinum) have strong stability in very aggressive environments such as strong acids. When metal is exposed to a natural environment, it will revert to its natural state by corroding to form compounds. In acids or other aggressive solutions attack may be rapid, while in ordinary air atmosphere the attack may be slow due to the formation of protective corrosion deposits. Metals that are not homogenous in nature or those that have rough surfaces create potential sites for the initiation of corrosion. Corrosion is responsible for numerous losses in engineering industries. To protect metallic materials, maintenance operations like pickling and cleaning are employed. Aggressive hydrochloric acid used for pickling and cleaning operations often corrodes the metallic structures. Among the various techniques of controlling corrosion, application of an inhibitor is one of the best known techniques. ${ }^{1-2}$ The quest for corrosion control by the application of an inhibitor is widely acceptable to maintain the stability of metallic structures. ${ }^{3}$ Organic compounds containing oxygen, nitrogen and phosphorus atoms are presumed to have strong ability to inhibit corrosion of metals in acid environments. ${ }^{4}$

Different plants extract have successfully been evaluated for * To whom correspondence should be addressed. E-mail: anadebechika@ gmail.com their corrosion inhibiting performance. The corrosion inhibiting strength of plants extract may be attributed to their phytochemical constituents. It has been observed that plant extracts are of great interest, because they are cheap, biodegradable, readily available and eco-friendly. ${ }^{5-10}$ Due to their potential benefits, some plants have been examined as green inhibitors for metals in alkaline and acid environment. ${ }^{11-12}$ Among the various plant extracts, such as Thevetia peruviana extract gave $81 \%$ efficiency for carbon steel in $1 \mathrm{M} \mathrm{HCl}$ at $300 \mathrm{ppm}^{13}$ Ocimium gratissium extract gave $82.9 \%$ efficiency for aluminum in $\mathrm{HCl}$ at inhibitor concentration of $1.3 \mathrm{~g} \mathrm{~L}^{-1},{ }^{14}$ Chromolaena odorata and Tridax procumbens extract gave $99.8 \%$ and $99.9 \%$ inhibition efficiency for stainless steel in acidizing oil field environment at 400 ppm, respectively. ${ }^{15}$

This article is a continuation of previous works. ${ }^{5,6}$ RSM (response surface methodology) a statistical tool, was used for modelling and solving of the problem in which a response of interest is affected by different variables. The aim is to optimize the response (output) which is also affected by different independent variables (input). Also to systematically investigate and obtain new insight on the inhibition performance of an ethanol extract of bitter kola leaf on mild steel corrosion in the acid environment.

\section{Experimental}

\subsection{Preparation of the Plant}

Bitter kola leaf was collected from Uli in Anambra State of Nigeria. The leaves were sun-dried for 4 days and later ground 
into powder form. In the process of extraction, $30 \mathrm{~g}$ bitter kola leaves were weighed and immersed in $1000 \mathrm{~mL}$ of ethanol for $48 \mathrm{~h}$ followed by separation. The stock solution of the extract was subjected to phytochemical analysis to determine the presence of alkaloids, phenolics, steroids, tannins, saponins and flavonoids. The $\mathrm{HCl}$ (JHD) and ethanol (JHD) used for the practical were of high grade.

\subsection{Metals Preparation}

Corrosion studies were performed on mild steel of compositions $\mathrm{P}(0.02 \%), \mathrm{Mn}(0.11 \%), \mathrm{Si}(0.02 \%), \mathrm{S}(0.02 \%) \mathrm{Cu}(0.01 \%)$, $\mathrm{C}(0.23 \%), \mathrm{Ni}(0.02 \%), \mathrm{Cr}(0.01 \%)$ and $\mathrm{Fe}(99.56 \%)$. Prior to corrosion process, the mild steel was mechanically cut into coupons $(5 \mathrm{~cm} \times 4 \mathrm{~cm} \times 0.1 \mathrm{~cm})$. The surface of each coupon were then polished using 800, 1200 and 220 emery papers to obtain a smooth area. The coupons were further degreased with acetone rinsed with distilled water to remove debris and dry in warm air according to previous work done. ${ }^{16}$

\subsection{FTIR Analysis}

Prior to the experiment, FTIR analysis was carried out on the neat sample (BKL) to identify the active functional group. Metal coupons were further introduced in the inhibited medium. After the corrosion study, the corrosion products were collected with sample bottle mixed with KBR and subjected to Fourier transform infrared spectroscopy using (SHIMADZU Model IR affinity-1, S/N A213747013651) to identify the functional group in the corrosion products.

\subsection{Thermometric Approach}

The experiment was performed using thermostat at $30^{\circ} \mathrm{C}$ for the metal specimen. The temperature of the system where the mild steel was immersed was noted regularly until a stabilized temperature value was reached. The reaction number $(\mathrm{RN})$ was calculated using Equation (1) as contained in other similar protocols. ${ }^{17-18}$

$$
\mathrm{RN}=\frac{\mathrm{T}_{\mathrm{m}}-\mathrm{T}_{\mathrm{i}}}{\mathrm{t}}
$$

where $T_{m}$ and $T_{i}$ denote the maximum and initial temperatures in ${ }^{\circ} \mathrm{C}, \mathrm{t}$ is the duration in minutes taken to reach $\mathrm{T}_{\mathrm{m}}$.

The inhibition efficiency was calculated by applying Equation 2 below

$$
\mathrm{IE} \%=1-\frac{\mathrm{RN}_{\mathrm{add}}}{\mathrm{RN}_{\text {free }}} \times 100
$$

\subsection{Gravimetric Method}

Gravimetric technique was performed at temperatures of 300 $\mathrm{K}, 312 \mathrm{~K}$ and $324 \mathrm{~K}$, respectively. As previously expressed ${ }^{5,6}$ mild steel coupons were weighed and introduced in $250 \mathrm{~mL}$ beakers containing $200 \mathrm{~mL}$ of $1.2 \mathrm{M} \mathrm{HCl}$ with inhibitor concentrations range of $0.3 \mathrm{~g} \mathrm{~L}^{-1}, 0.6 \mathrm{~g} \mathrm{~L}^{-1}$, and $0.9 \mathrm{~g} \mathrm{~L}^{-1}$. The variation in the initial and final weight was studied for uninhibited and inhibited test solution. At the end of corrosion study the coupons were removed, dipped in acetone, cleaned and finally re-weighed. The experimental data were recorded. The weight loss $(\Delta \mathrm{w})$, corrosion rate (CR), inhibition efficiency (IE) and surface coverage $(\theta)$ were calculated using Equations (3), (4), (5) and (6), respectively. ${ }^{19}$

$$
\begin{aligned}
& \Delta \mathrm{w}=\mathrm{w}_{\mathrm{i}}-\mathrm{w}_{\mathrm{f}} \\
& \mathrm{CR}=\frac{\mathrm{w}_{\mathrm{bl}}-\mathrm{w}_{\text {inh }}}{\mathrm{A}} \times \mathrm{t}
\end{aligned}
$$

$$
\begin{aligned}
& \text { IE } \%=\frac{w_{b l}-w_{\text {inh }}}{w_{b l}} \times 100 \\
& \theta=\frac{w_{b l}-w_{i n h}}{w_{b l}}
\end{aligned}
$$

where $w_{i}$ and $w_{f}$ are initial and final weight of the coupons. $\mathrm{w}_{\mathrm{bl}}$ and $\mathrm{w}_{\mathrm{inh}}$ are the weight loss values obtained in the blank and inhibited environments. A is the total area of the mild steel sample and $\mathbf{t}$ is the time of immersion.

\subsection{Determination of Activation and Heat of Adsorption}

Considering corrosion rates of the mild steel at $T_{1}$ and $T_{2}$ as $C R_{1}$ and $\mathrm{CR}_{2}$, Equation (7) was used to predict the activation energy. The heat of adsorption $\mathrm{Q}_{\mathrm{ads}}\left(\mathrm{kJ} \mathrm{mol}^{-1}\right)$ was calculated using Equation $(8){ }^{20}$

$$
\begin{aligned}
& \ln \left(\mathrm{CR}_{2} / \mathrm{CR}_{2}=\left(\frac{\mathrm{E}_{\mathrm{a}}}{2.303 \mathrm{R}}\right)\left(\frac{1}{\mathrm{~T}_{1}}-\frac{1}{\mathrm{~T}_{2}}\right)\right. \\
& \mathrm{Q}_{\text {ads }}=2.303 \mathrm{R}\left[\log \left(\frac{\theta_{2}}{1-\theta_{2}}\right)-\log \left(\frac{\theta_{1}}{1-\theta_{1}}\right)\right] \times \frac{\mathrm{T}_{2}-\mathrm{T}_{1}}{\mathrm{~T}_{2}-\mathrm{T}_{1}}
\end{aligned}
$$

where $\mathrm{E}_{\mathrm{a}}$ is the activation energy, $\mathrm{R}$ denotes gas constant, $\theta_{1}$ and $\theta_{2}$ represent degree of surface coverage at temperature $\mathrm{T}_{1}$ and $\mathrm{T}_{2}$. $\theta_{1}$ and $\theta_{2}$ were determined using Equation (6) of section 2.5

\subsubsection{Adsorption Isotherms}

To determine the values of the thermodynamic properties, data of concentration and surface coverage were fitted into Langmuir, Frumkin, Temkin and Flory-Huggins isotherms of Equations (9), (10), (11) and (12), respectively.

$$
\begin{aligned}
& \frac{C}{\theta}=\frac{1}{K_{\mathrm{ads}}}+C \\
& \log \left[C \times\left(\frac{\theta}{1-\theta}\right)\right]=2.303 \log \mathrm{K}+2 \alpha \theta \\
& \theta=\left(\frac{2.303 \log \mathrm{K}}{2 \mathrm{a}}-\frac{2.303 \log \mathrm{C}}{2 \mathrm{a}}\right) \\
& \log \left[\left(\frac{\theta}{\mathrm{C}}\right)\right]=\log \mathrm{K}+\mathrm{x} \log (1-\theta)
\end{aligned}
$$

where $\mathbf{C}$ represent concentration of inhibitor, $\mathbf{K}_{\mathrm{ads}}$ denotes adsorption equilibrium , $\alpha$ is the lateral interaction term explaining the nature of adsorbed layer, $\mathbf{a}$ is the attractive parameter, $\mathbf{x}$ is size parameter (this is the measure of the quantity of the adsorbed water molecules sub-planted by inhibitor molecules). Then the free energy of adsorption $\left(\Delta \mathrm{G}_{\mathrm{ads}}\right)$ was evaluated using Equation (13).

$$
\Delta \mathrm{G}_{\mathrm{ads}}=-2.303 \mathrm{RT} \log (55.5 \mathrm{~K})
$$

\subsection{Electrochemical Technique}

Thorough electrochemical analysis was performed with the aid of a potentiostat/galvanostat 263 electrochemical system workstation. A graphite rod and a saturated calomel electrode (SCE) were used as reference electrodes. A mild steel specimen of $1 \mathrm{~cm}^{2}$ dimension was used as working electrode.The experiment was performed in aerated and unstirred solution at the end of $30 \mathrm{~min}$ of immersion, this makes the solution to reach steady state. Temperature was set at $30 \pm 1{ }^{\circ} \mathrm{C}$. Polarization studies were performed in the range $\pm 250 \mathrm{mV}$ versus corrosion potential at a scan rate of $0.333 \mathrm{mV} / \mathrm{s}$. The efficiency was evaluated using Equation (14).

$$
\text { IE } \%=\frac{i_{\text {corr(bl) }}-i_{\text {corr(inh) }}}{i_{\text {corr(bl) }}}
$$

where (bl) and (inh) are the current density values in the absence and presence of inhibitor, respectively. 


\subsection{Scanning Electron Microscopy}

Morphological analysis of the corroded coupons were carried out at Chemical Engineering Department Ahmadu Bello University, Zaria, using the scanning electron microscope (SEM of model no MVE016477830, Manufactured by Phenom-world Eindhoven, Netherlands). The surfaces of the mild steel immersed in inhibited and uninhibited acid environments were investigated.

\section{Results and Discussion}

\subsection{Spectroscopic Analysis of Bitter Kola Leaf Extract and Corrosion Product}

Bitter kola leaf extract with the corrosion product formed after immersion in $1.2 \mathrm{M} \mathrm{HCl}$ solution were investigated using FTIR technique. The peak numbers in the pure extract and the extract with the corrosion products are presented in Table 1 . The peak numbers indicate the functional groups of the extract as expressed by other research work, ${ }^{21}$ the stretched $\mathrm{O}-\mathrm{H}$ at $3601.14 \mathrm{~cm}^{-1}$ peak of the pure extract shifted to $3547.1 \mathrm{~cm}^{-1}$ in the corrosion product. Also, stretched C-H, N-H and stretched C $=\mathrm{C}$ recorded changes in peaks and intensities. The change in the peaks values revealed that there was a correlation between the mild steel surface and functional groups present in the bitter kola leaf extract. The variation of the peak numbers shows that some peaks deviated, while some disappeared. ${ }^{22}$

\subsection{Thermometric Results of the Corrosion Inhibition Process}

Influence of inhibitor concentration (BKL) on RN and the inhibition efficiency (IE) of mild steel in $\mathrm{HCl}$ are presented in Table 2. Addition in concentration of the inhibitor reduces the $\mathrm{RN}$, and also increased concentration enhances the inhibition efficiency. ${ }^{17}$ Maximum inhibition efficiency of $86.81 \%$ was attained at $0.9 \mathrm{~g} \mathrm{~L}^{-1}$ of inhibitor.

\subsection{Result of Gravimetric Method Using One Factor at a Time.}

Results of the weight loss, corrosion rate, inhibition efficiency and surface coverage of mild steel in $\mathrm{HCl}$ are shown in Table 3. Bitter kola leaf extract gave high inhibition efficiency (IE) which is higher than inhibition efficiencies of previously used plant extracts. ${ }^{5,6}$ The inhibition level increased with an increase in concentration of the plant extract, due to the active constituents that covers the metal surface. Similarly, the surface coverage increased by enhancing the concentration of the extract because increase in the inhibitor concentration increases the availability/ adsorption of the active components of the inhibitor onto the corroding metal surface. On the contrary, surface coverage decreased with an increased in temperature, reason being that increase in temperature tends to disperse the extract from the surface of the mild steel (breaks the heterocyclic bond of the extracts thereby reducing the surface coverage). This observation is in agreement with research work. ${ }^{23}$ Optimum inhibition efficiency of $90 \%$ was recorded at temperature of $300 \mathrm{~K}$, and $0.9 \mathrm{~g} \mathrm{~L}^{-1}$ at $21 \mathrm{~h}$ immersion time which also implies that corrosion and inhibition process depends on time of expose with increasing the concentration of the extract molecules. It showed that bitter kola leaf extract is good for corrosion control of mild steel in $\mathrm{HCl}$ solution using greener approach.

\subsection{Activation Energy and Heat of Adsorption Studies}

$E_{a}$ and $Q_{a d s}$ for the corrosion control of mild steel in $\mathrm{HCl}$ with bitter kola leaf extract are shown in Table 4. From the table below, calculated $\mathrm{E}_{\mathrm{a}}$ value for the inhibited solution with bitter kola extract is 39.503 and $53.750 \mathrm{KJ} \mathrm{mol}^{-1}$ in the presence of inhibitor concentration of 0.6 and $0.9 \mathrm{~g} \mathrm{~L}^{-1}$ while in 0.1 and $0.2 \mathrm{~g} \mathrm{~L}^{-1}$ inhibitor concentration, the activation energies are 20.525 and $25.235 \mathrm{KJ} \mathrm{mol}^{-1}$. The results of the activation energy prove that the electrochemical reaction of mild steel in presence of inhibitor was obstructed ${ }^{24}$ due to the heterocyclic compounds present in bitter kola extract which guide the metal surface from acid attack due to the adhesion of the film layer on the metal surface, the film layer is stronger than the degradation of the metal surface which is an exothermic reaction. ${ }^{25}$

\subsubsection{The Adsorption Parameters for the Corrosion Inhibition Study}

Generally, it is well known that plants extracts display their inhibitive behaviour on the steel surface through the process of adhesion. The adsorption of the inhibitor is attributed to the heterocyclic compounds in the extract thereby obstructing the invading of electrochemical reactions by forming a protective film layer which functions as a barrier, preventing the ingress of the corrodent onto the metal surface. Furthermore, in-depth knowledge of the adsorption character of an inhibitor is vital for proper understanding of the kinetics process. An adsorption isotherm explains the mutual interactions between the surface coverage of the metal with the adsorbed extract molecules and the concentration of extract molecules in acid media. Evaluation of behaviour of the adsorbent type of inhibitor can be predicted by fitting the data in the following adsorption isotherms, Langmuir, Frumkin, Temkin and Flory-Huggins isotherms. The plots are presented in Figs. 1-4) (trend line functions of Microsoft

Table 1 FTIR analysis of pure bitter kola leaf extract and corrosion products in $1.2 \mathrm{M} \mathrm{HCl}$.

\begin{tabular}{|c|c|c|c|}
\hline \multicolumn{2}{|c|}{ Pure bitter kola leaf extract } & \multicolumn{2}{|c|}{$\begin{array}{l}\text { Corrosion products of mild steel in } 1.2 \mathrm{M} \mathrm{HCl} \text { with } \\
0.9 \mathrm{~g} \mathrm{~L}^{-1} \mathrm{BKL} \text { extract }\end{array}$} \\
\hline Peak $\left(\mathrm{cm}^{-1}\right)$ & Assignments & Peak $\left(\mathrm{cm}^{-1}\right)$ & Assignments \\
\hline 3601.1 & O-H stretch of alcohols and phenols & 3632.0 & O-H stretch of alcohols and phenols \\
\hline $3450.6-3168.8$ & N-H stretch of amines & $3477.1-3330.9$ & N-H stretch of amines \\
\hline $3045.3-2960.3$ & C-H stretch of alkanes, cycloalkanes & $3076.1-2952.6$ & C-H stretch of alkanes, cycloalkanes \\
\hline $2856.1-2732.6$ & C-H stretch of aldehydes & $2767.3-2705.6$ & C-H stretch of aldehydes \\
\hline $1875.7-1817.8$ & $\mathrm{C}=\mathrm{O}$ stretch of acid anhydrides & 1536.0 & $\mathrm{~N}=\mathrm{O}$ stretch of nitro compound \\
\hline 1748.3 & Cyclic carbonyl group & 1443.4 & C-H deformation alkanes, cycloalkanes \\
\hline 1593.9 & N-H deformation (amide) carbonyl group & $1289-1223.3$ & $\mathrm{~N}=\mathrm{O}$ stretch of nitroso \\
\hline 1474.2 & C-H deformation alkanes, cycloalkanes & 1053.5 & C-O stretch of ethers \\
\hline 1381.6-1319.8 & $\mathrm{NO}_{2}$ stretching nitro & & \\
\hline $1111.4-1007.2$ & C-O stretch of ethers & & \\
\hline
\end{tabular}


Table 2 Influence of concentration of bitter kola leaf extract on the IE (\%) of mild steel in $1.2 \mathrm{M} \mathrm{HCl}$.

\begin{tabular}{ccc}
\hline Inhibitor concentration $/ \mathrm{g} \mathrm{L}^{-1}$ & $\mathrm{RN} /{ }^{\circ} \mathrm{C} \mathrm{min}^{-1}$ & $\mathrm{IE} / \%$ \\
\hline 0.0 & 0.02758 & \\
0.1 & 0.01691 & 38.68 \\
0.2 & 0.01192 & 56.78 \\
0.3 & 0.00721 & 73.85 \\
0.6 & 0.00425 & 84.60 \\
0.9 & 0.00364 & 86.81
\end{tabular}

Excel was used to generate the mathematical equations). Accordingly, linear graphs were observed. It shows the relationship between the extract molecules and the coverage of the metal surface. The Langmuir isotherm has highest value of $R^{2}$ (0.996), indicating strong support to Langmuir adsorption isotherm. ${ }^{26,27}$ Comparing the equations in Figs. 1-4 with the isotherm Equations 9, 10, 11 and 12 the adsorption properties $\mathrm{K}$, $\alpha$, $\mathrm{a}$ and $\mathrm{x}$ were obtained. From the Frumkin adsorption parameter, the lateral interaction term (a) gives positive values suggesting good behaviour of the inhibitor on the mild steel surface, ${ }^{6}$ from Temkin adsorption parameter, the attractive parameter value (a) is negative, showing that repulsion exists in the adsorption layer. ${ }^{26}$ The value of the size parameter $(\mathrm{x})$ is positive proving that the adsorbed species of the BKL extract is bulky. ${ }^{20}$ The isotherms and the values of these parameters are presented in Table 5.

\subsection{Polarization Measurements}

A clear polarization curve is shown in Fig. 5. Polarization measurements were performed to evaluate the performance of BKL in obstructing the electrochemical reactions. The mild steel coupon is seen to display strong dissolution without evidence of passivation in the studied potential range in $\mathrm{HCl}$ solutions. ${ }^{28} \mathrm{It}$ was equally observed that when BKL was immersed in the inhibited solution $I_{\text {corr }}$ reduces compared to the uninhibited solution. Small deviation on $\mathrm{E}_{\text {corr }}$ was noted. If the displacement in $\mathrm{E}_{\text {corr }}$ is above $85 \mathrm{mV}$ we could classify the inhibitor as anodic or cathodic and if the displacement is below $85 \mathrm{mV}$ the inhibitor may be seen as a mixed-mode. ${ }^{29}$ The corresponding electrochemical parameters namely, corrosion potential $\left(\mathrm{E}_{\text {corr }}\right)$ and corrosion current density $\left(\mathrm{I}_{\text {corr }}\right)$ were generated and their values are presented in Table 6. The maximum displacement in $\mathrm{E}_{\text {corr }}$ value are less than $85 \mathrm{mV}$, bitter kola leaf extract behaved as a mixed-mode inhibitor. ${ }^{30}$ However, the extracts function as a mixed-mode inhibitor with predominant cathodic effect in $1.2 \mathrm{M}$ $\mathrm{HCl}$. These effects become more noticeable at higher concentrations. The values of the corrosion current density in the absence $\left(\mathrm{I}_{\text {corr uninh }}\right)$ and presence of inhibitor $\left(\mathrm{I}_{\text {corr inh }}\right)$ were used to estimate the inhibition efficiency.

\subsection{Electrochemical Impedance Spectroscopy (EIS)}

Impedance spectra of mild steel in $\mathrm{HCl}$ solution at various concentrations of the inhibitor are shown in Fig. 6. The impedance measurements are most suitable for obtaining detailed mechanistic insights into corrosion process. The plot in each situation constitute of a single depressed capacitive semicircle in the elevated frequency area. ${ }^{31,32}$ It occurs due to coarseness of the mild steel surface. ${ }^{33,34}$ The electrochemical impedance parameters of the corrosion inhibition of mild Steel in $\mathrm{HCl}$ solution are shown in Table 7. Due to a modification in the presence of the inhibitor, the values of $C_{d l}$ decreased more than the one seen in the absence of the inhibitor. Charge transfer resistance and
Table 3 Gravimetric results of metal specimen in $1.2 \mathrm{M} \mathrm{HCl}$ with bitter kola leaf extract.

\begin{tabular}{|c|c|c|c|c|c|c|}
\hline $\begin{array}{l}\text { Time } \\
\text { /h }\end{array}$ & $\underset{/ K}{\text { Temp. }}$ & $\begin{array}{l}\text { IC } \\
/ \mathrm{g} \mathrm{L}^{-1}\end{array}$ & $\begin{array}{l}\text { Wt loss } \\
/ \mathrm{g}\end{array}$ & CR & $\mathrm{IE} / \%$ & SC \\
\hline \multirow[t]{12}{*}{21} & \multirow[t]{4}{*}{300} & 0.0 & 0.20 & 0.476 & & \\
\hline & & 0.3 & 0.09 & 0.214 & 55 & 0.55 \\
\hline & & 0.6 & 0.04 & 0.095 & 80 & 0.8 \\
\hline & & 0.9 & 0.02 & 0.048 & 90 & 0.9 \\
\hline & \multirow[t]{4}{*}{312} & 0.0 & 0.23 & 0.548 & & \\
\hline & & 0.3 & 0.11 & 0.262 & 52.17 & 0.5217 \\
\hline & & 0.6 & 0.05 & 0.119 & 78.26 & 0.7826 \\
\hline & & 0.9 & 0.43 & 1.024 & 76.5 & 0.765 \\
\hline & \multirow[t]{4}{*}{324} & 0.0 & 0.24 & 0.571 & & \\
\hline & & 0.3 & 0.13 & 0.31 & 45.83 & 0.4583 \\
\hline & & 0.6 & 0.08 & 0.19 & 66.67 & 0.6667 \\
\hline & & 0.9 & 0.06 & 0.143 & 75 & 0.75 \\
\hline \multirow[t]{12}{*}{14} & \multirow[t]{4}{*}{300} & 0.0 & 0.13 & 0.464 & & \\
\hline & & 0.3 & 0.06 & 0.214 & 53.85 & 0.5385 \\
\hline & & 0.6 & 0.04 & 0.143 & 69.23 & 0.6923 \\
\hline & & 0.9 & 0.03 & 0.107 & 76.92 & 0.7692 \\
\hline & \multirow[t]{4}{*}{312} & 0.0 & 0.16 & 0.571 & & \\
\hline & & 0.3 & 0.08 & 0.286 & 50 & 0.5 \\
\hline & & 0.6 & 0.05 & 0.179 & 69 & 0.69 \\
\hline & & 0.9 & 0.04 & 0.143 & 75 & 0.75 \\
\hline & \multirow[t]{4}{*}{324} & 0.0 & 0.17 & 0.607 & & \\
\hline & & 0.3 & 0.09 & 0.321 & 47.06 & 0.4706 \\
\hline & & 0.6 & 0.07 & 0.25 & 58.82 & 0.5882 \\
\hline & & 0.9 & 0.05 & 0.179 & 70.59 & 0.7059 \\
\hline \multirow[t]{12}{*}{7} & \multirow[t]{4}{*}{300} & 0.0 & 0.11 & 0.786 & & \\
\hline & & 0.3 & 0.06 & 0.429 & 45.45 & 0.4545 \\
\hline & & 0.6 & 0.04 & 0.286 & 63.64 & 0.6364 \\
\hline & & 0.9 & 0.03 & 0.214 & 72.73 & 0.7273 \\
\hline & \multirow[t]{4}{*}{312} & 0.0 & 0.12 & 0.857 & & \\
\hline & & 0.3 & 0.07 & 0.5 & 41.67 & 0.4167 \\
\hline & & 0.6 & 0.05 & 0.357 & 58.33 & 0.5833 \\
\hline & & 0.9 & 0.04 & 0.286 & 66.67 & 0.6667 \\
\hline & \multirow[t]{4}{*}{324} & 0.0 & 0.13 & 0.929 & & \\
\hline & & 0.3 & 0.09 & 0.643 & 30.70 & 0.3077 \\
\hline & & 0.6 & 0.06 & 0.429 & 53.85 & 0.5385 \\
\hline & & 0.9 & 0.05 & 0.357 & 61.54 & 0.6154 \\
\hline
\end{tabular}

double layer capacitance display the opposite direction, according to Helmholtz model

$$
\mathrm{C}_{\mathrm{dl}}=\frac{\varepsilon \varepsilon_{\mathrm{o}} \mathrm{A}}{\delta}
$$

The change in $\mathrm{C}_{\mathrm{dl}}$ value occurs due to a reduction in the dielectric constant and an increase in the double layer thickness can be assigned to the adhesion of inhibitor on the corroding mild steel surface. ${ }^{35-39}$ The $C_{\mathrm{dl}}$ is defined as double layer capacitance, $\varepsilon$-dielectric constant of the medium, $\varepsilon_{\mathrm{o}}$ the vacuum permittivity,

Table 4 Activation energy and heat of adsorption data.

\begin{tabular}{ccc}
\hline Inhibitor concentration & $\begin{array}{c}\text { Activation energy } \\
/ \mathrm{E}_{\mathrm{a}}\end{array}$ & $\begin{array}{c}\text { Heat of adsorption } \\
/ \mathrm{Q}_{\mathrm{ads}}\end{array}$ \\
\hline 0.1 & 20.52583 & -39.604 \\
0.2 & 25.23518 & -10.012 \\
0.3 & 26.04549 & -84.052 \\
0.6 & 39.50391 & -15.030 \\
0.9 & 53.75074 & -21.414 \\
\hline
\end{tabular}




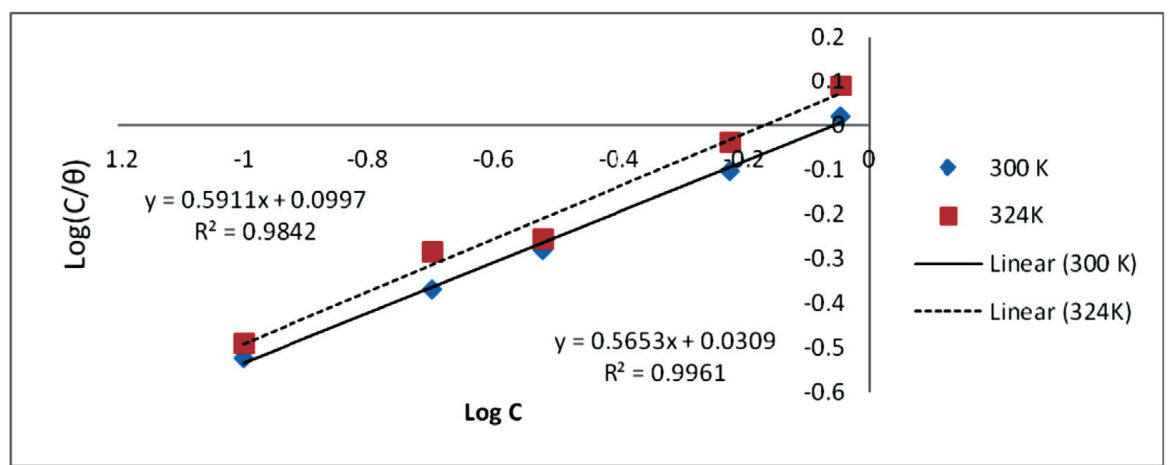

Figure 1 Plot of Langmuir for mild steel in $\mathrm{HCl}$ with BKL extract.
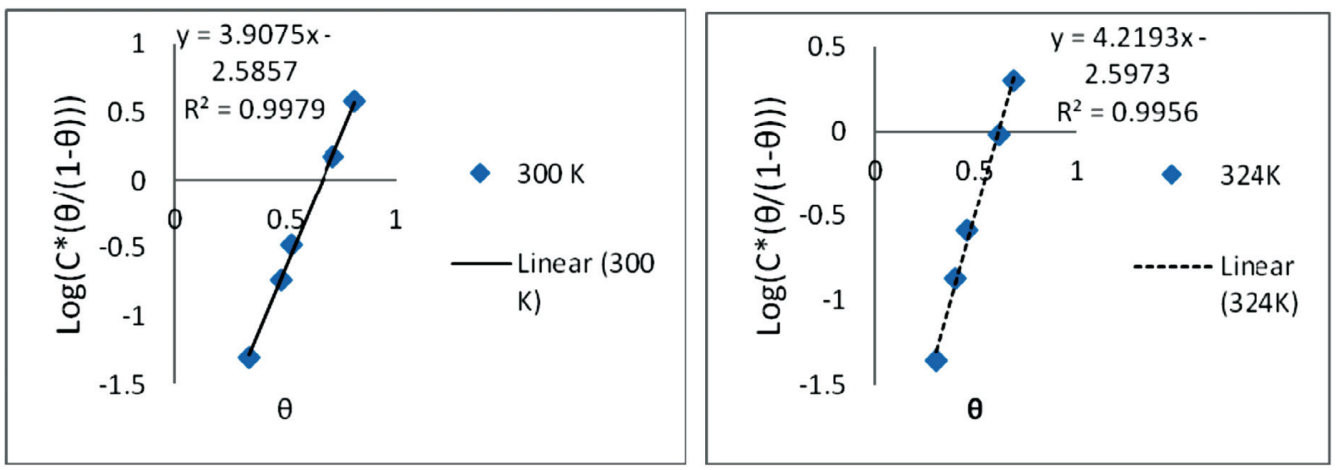

Figure 2 Plot of Frumkin for mild steel in $\mathrm{HCl}$ with BKL extract.

A is the electrode area, $\delta$ is the thickness of the interfacial layer. Accordingly, addition of the extract in test solution gave rise in the magnitude of the Nyquist semicircle. It showed effective inhibition of the corrosion process. Increased concentration of the extracts in each case did not affect the impedance mechanism. The observed increased in $R_{c t}$ is due to the adhesion of a film layer on the metal surface which includes substitution of water molecules by the extract species. $R_{c t}$ is defined as the charge transfer resistance.

\subsection{Result of Gravimetric Method using Response Surface} Methodology.

Design expert version (10) software was used to design the experiment having 30 experimental runs in order to systemati-

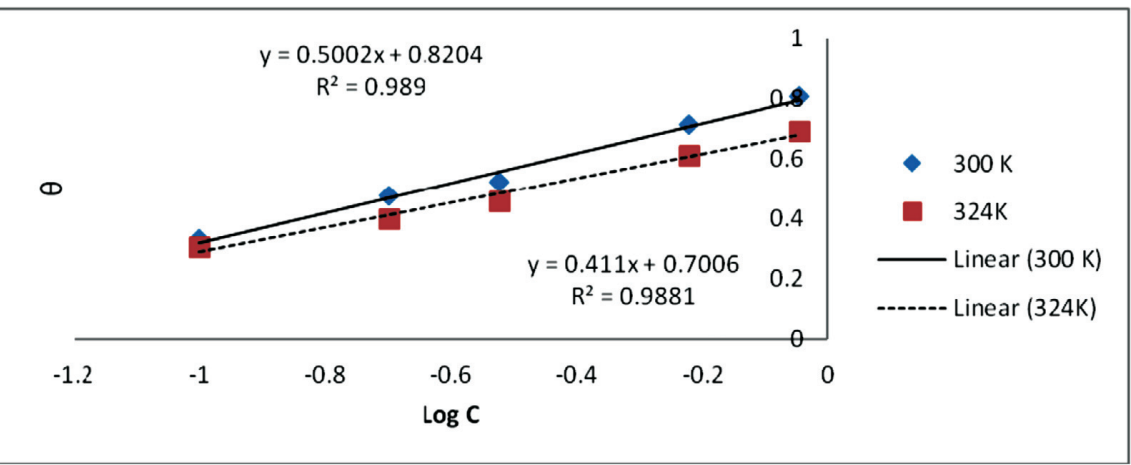

Figure 3 Plot of Temkin for mild steel in $\mathrm{HCl}$ with BKL extract.
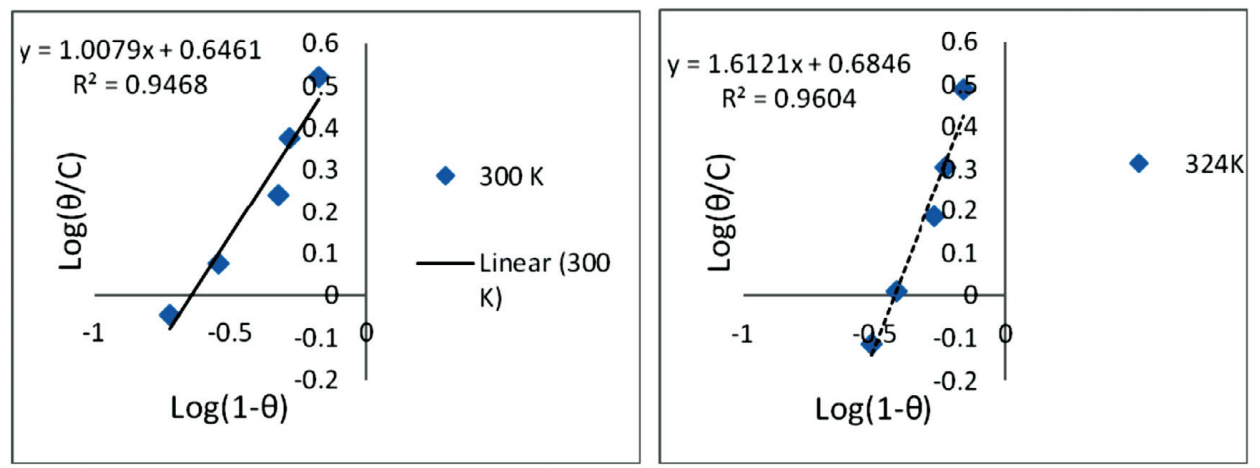

Figure 4 Plot of Flory-Huggins for mild steel in $\mathrm{HCl}$ with BKL extract. 
Table 5 Adsorption parameters for the corrosion inhibition of mild steel in $\mathrm{HCl}$ with extract.

\begin{tabular}{lccccr}
\hline Adsorption & $\begin{array}{c}\text { Temp } \\
/ \mathrm{K}\end{array}$ & $\mathrm{R}^{2}$ & $\log \mathrm{K}$ & $\begin{array}{c}\mathrm{DG}_{\text {ads }} \\
/ \mathrm{kJ} \mathrm{mol}^{-1}\end{array}$ & $\begin{array}{r}\text { Isotherm } \\
\text { property }\end{array}$ \\
\hline Langmuir & 300 & 0.996 & -0.064 & -9.65 & \\
& 324 & 0.984 & -0.136 & -9.98 & \\
Frumkin & 300 & 0.998 & -2.585 & -3.57 & $\alpha 2.109$ \\
& 324 & 0.991 & -1.127 & -3.82 & 1.953 \\
Temkim & 300 & 0.995 & -1.640 & -0.60 & $\mathrm{a}-2.801$ \\
& 324 & 0.975 & -1.703 & -0.25 & -2.303 \\
Flory- & 300 & 0.965 & 0.646 & -13.7 & $\times 1.612$ \\
Huggins & 324 & 0.939 & 0.684 & -15.0 & 1.007 \\
\hline
\end{tabular}

cally have an insight on the stability of the inhibitor within the studied range and to predict the optimum range for controlling of mild steel corrosion in different test solutions as indicated in Table 8 . The independent variables considered in this experiment were Acid concentration (AC), Inhibitor concentration (IC), Temperature (T), and time (t). From Table 8 , it was noted

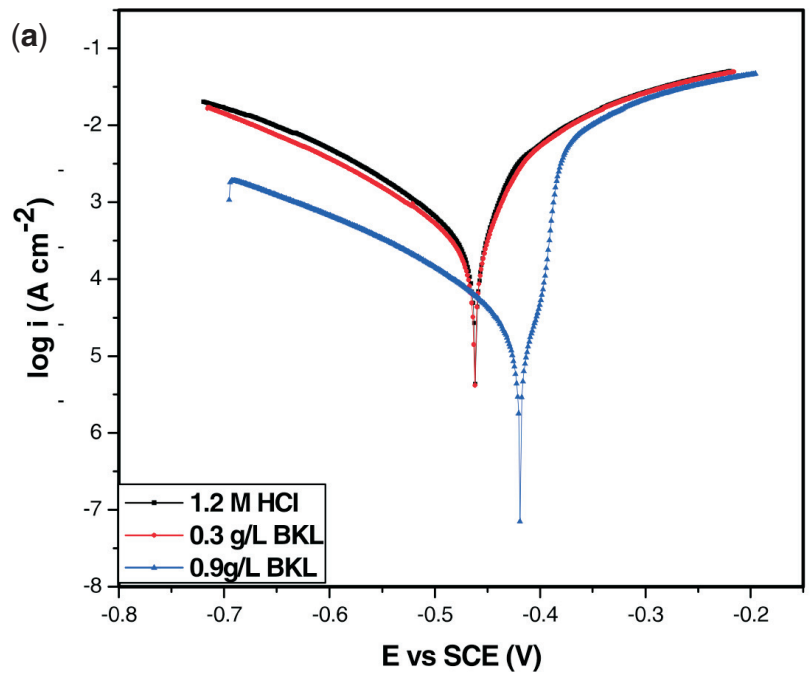

Table 6 The parameter from Tafel polarization measurements.

\begin{tabular}{lcccc}
\hline System & $\mathrm{E}_{\text {corr }}$ & $\mathrm{I}_{\text {corr }}$ & $\theta$ & $\mathrm{IE} / \%$ \\
\hline $1.2 \mathrm{M} \mathrm{HCl}$ & -566.4 & 183 & & \\
$1.2 \mathrm{M} \mathrm{HCl}+0.3 \mathrm{~g} \mathrm{~L}^{-1} \mathrm{BKL}$ & -454.9 & 125.1 & 0.884 & 31.7 \\
$1.2 \mathrm{M} \mathrm{HCl}+0.9 \mathrm{~g} \mathrm{~L}^{-1} \mathrm{BKL}$ & -456.9 & 19.3 & 0.927 & 89.5 \\
$0.3 \mathrm{M} \mathrm{HCl}$ & -466.8 & 89.6 & & \\
$0.3 \mathrm{M} \mathrm{HCl}+0.3 \mathrm{~g} \mathrm{~L}^{-1} \mathrm{BKL}$ & -476.5 & 46.2 & 0.401 & 48.4 \\
$0.3 \mathrm{M} \mathrm{HCl}+0.9 \mathrm{~g} \mathrm{~L}^{-1} \mathrm{BKL}$ & -474.3 & 16.8 & 0.543 & 81.3 \\
\hline
\end{tabular}

that inhibition efficiency stabilizes by enhancing the inhibitor concentration of the extract molecules thereby giving the optimum range of $88.24 \%$. The 3-D plots for IE \% of BKL extract on mild steel in $\mathrm{HCl}$ environment is presented in Fig. 7. The predicted versus actual inhibition efficiency plot displayed a linear graph Fig. 7A, showing that the proposed model is able to evaluate the inhibition process. The 3-D plots (Fig. 7B-D) showed the relationship between the factors influencing the corrosion process and the efficacy of BKL. The characteristics of the 3-D surfaces plot imply that there is complementary relationship among the considered factors of the corrosion process.

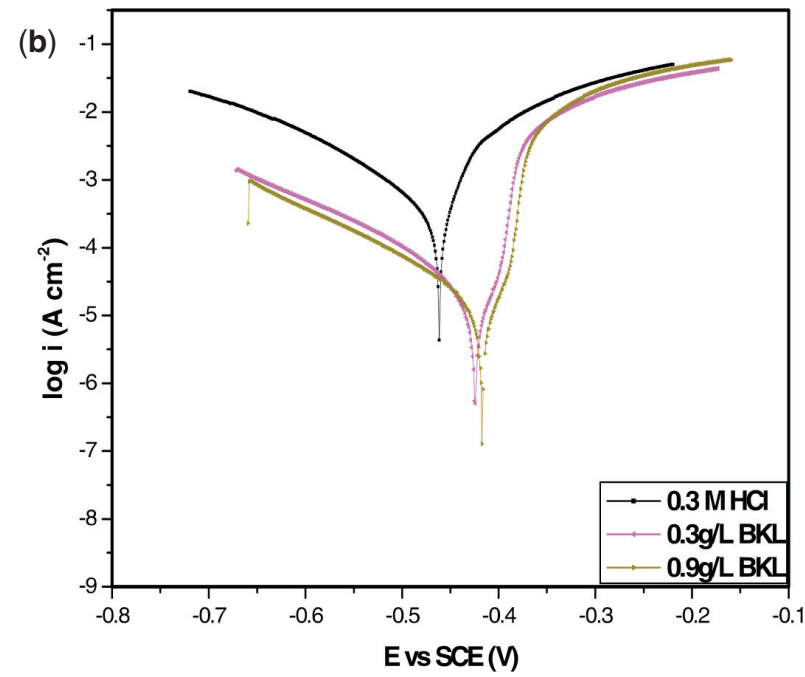

Figure 5 Potentiodynamic polarization curves of Mild steel in (a) $1.2 \mathrm{M} \mathrm{HCl}$ and (b) $0.3 \mathrm{MHCl}$ in the absence and presence of bitter kola leaf extract.
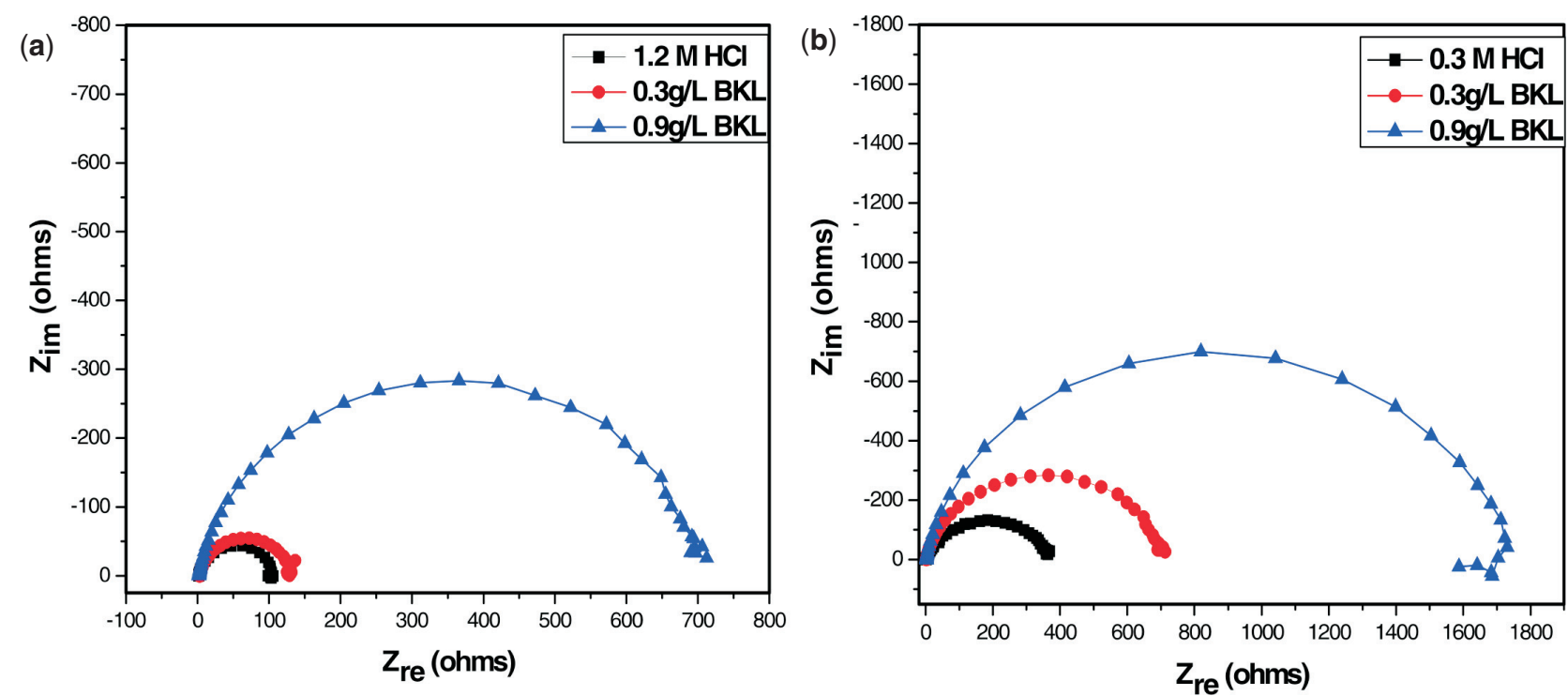

Figure 6 Impedance spectra of mild steel in (a) $1.2 \mathrm{M} \mathrm{HCl}$ and (b) $0.3 \mathrm{M} \mathrm{HCl}$ solution in the absence and presence of bitter kola leaf extract. 
Table 7 Impedance parameters of mild steel in $\mathrm{HCl}$.

\begin{tabular}{lccccc}
\hline System & $\mathrm{R}_{\mathrm{s}} / \Omega \mathrm{cm}^{2}$ & $\mathrm{R}_{\mathrm{ct}} / \Omega \mathrm{cm}^{2}$ & $\mathrm{~N}$ & $\mathrm{C}_{\mathrm{dl}} / \mathrm{F} \mathrm{cm}{ }^{2}$ & $\mathrm{IE} / \%$ \\
\hline $1.2 \mathrm{M} \mathrm{HCl}$ & 1.659 & 102.7 & 0.89 & $6.908 \mathrm{E}-5$ & \\
$1.2 \mathrm{M} \mathrm{HCl}+0.3 \mathrm{~g} \mathrm{~L}^{-1} \mathrm{BKL}$ & 2.007 & 145.2 & 0.84 & $7.094 \mathrm{E}-5$ & 29.2 \\
$1.2 \mathrm{M} \mathrm{HCl}+0.9 \mathrm{~g} \mathrm{~L}^{-1} \mathrm{BKL}$ & 1.923 & 700.1 & 0.83 & $7.075 \mathrm{E}-5$ & 85.3 \\
$0.3 \mathrm{M} \mathrm{HCl}$ & 2.329 & 380 & 0.89 & $7.985 \mathrm{E}-5$ & \\
$0.3 \mathrm{M} \mathrm{HCl}+0.3 \mathrm{~g} \mathrm{~L}^{-1} \mathrm{BKL}$ & 2.887 & 705 & 0.89 & $7.124 \mathrm{E}-5$ & 46.1 \\
$0.3 \mathrm{M} \mathrm{HCl}+0.9 \mathrm{~g} \mathrm{~L}^{-1} \mathrm{BKL}$ & 3.313 & 1780 & 0.89 & $6.987 \mathrm{E}-5$ & 78.7 \\
\hline
\end{tabular}

Table 8 CCD and results for the study of four experimental variables for BKL on mild steel.

\begin{tabular}{|c|c|c|c|c|c|c|c|c|}
\hline Std & Run & $\begin{array}{l}\mathrm{AC} \\
/ \mathrm{M}\end{array}$ & $\begin{array}{l}\mathrm{IC} \\
/ \mathrm{g} \mathrm{L}^{-1}\end{array}$ & $\begin{array}{l}\mathrm{T} \\
/ \mathrm{K}\end{array}$ & $\underset{/ \mathrm{h}}{\mathrm{Time}}$ & $\begin{array}{c}\text { Wt. loss } \\
/ \mathrm{g}\end{array}$ & CR & $\begin{array}{l}\mathrm{IE} \\
/ \%\end{array}$ \\
\hline 5 & 1 & 0.3 & 0.3 & 324 & 7 & 0.09 & 0.643 & 25 \\
\hline 6 & 2 & 1.2 & 0.3 & 324 & 7 & 0.10 & 0.714 & 33 \\
\hline 27 & 3 & 0.75 & 0.6 & 312 & 14 & 0.05 & 0.179 & 69 \\
\hline 17 & 4 & 0.3 & 0.6 & 312 & 14 & 0.08 & 0.286 & 42.86 \\
\hline 28 & 5 & 0.75 & 0.6 & 312 & 14 & 0.05 & 1.179 & 69 \\
\hline 30 & 6 & 0.75 & 0.6 & 312 & 14 & 0.05 & 1.179 & 69 \\
\hline 2 & 7 & 1.2 & 0.3 & 300 & 7 & 0.07 & 0.5 & 41.67 \\
\hline 13 & 8 & 0.3 & 0.3 & 324 & 21 & 0.13 & 0.31 & 40.91 \\
\hline 15 & 9 & 0.3 & 0.9 & 324 & 21 & 0.09 & 0.214 & 59.09 \\
\hline 14 & 10 & 1.2 & 0.3 & 324 & 21 & 0.14 & 0.333 & 46.15 \\
\hline 1 & 11 & 0.3 & 0.3 & 300 & 7 & 0.07 & 0.5 & 30 \\
\hline 16 & 12 & 1.2 & 0.9 & 324 & 21 & 0.08 & 0.19 & 69.23 \\
\hline 3 & 13 & 0.3 & 0.9 & 300 & 7 & 0.05 & 0.357 & 69.23 \\
\hline 22 & 14 & 0.75 & 0.6 & 324 & 14 & 0.07 & 0.25 & 58.82 \\
\hline 8 & 15 & 1.2 & 0.9 & 324 & 7 & 0.06 & 0.429 & 60 \\
\hline 10 & 16 & 1.2 & 0.3 & 300 & 21 & 0.10 & 0.238 & 52.38 \\
\hline 12 & 17 & 1.2 & 0.9 & 300 & 21 & 0.04 & 0.095 & 80 \\
\hline 18 & 18 & 1.2 & 0.6 & 312 & 14 & 0.07 & 0.25 & 61.11 \\
\hline 19 & 19 & 0.75 & 0.3 & 312 & 14 & 0.08 & 0.286 & 50 \\
\hline 25 & 20 & 0.75 & 0.6 & 312 & 14 & 0.05 & 0.179 & 69 \\
\hline 21 & 21 & 0.75 & 0.6 & 300 & 21 & 0.04 & 0.143 & 69.23 \\
\hline 7 & 22 & 0.3 & 0.9 & 324 & 7 & 0.07 & 0.5 & 41.67 \\
\hline 9 & 23 & 0.3 & 0.3 & 300 & 21 & 0.09 & 0.214 & 47.06 \\
\hline 24 & 24 & 0.75 & 0.6 & 312 & 21 & 0.05 & 0.119 & 78.26 \\
\hline 11 & 25 & 0.3 & 0.9 & 300 & 21 & 0.02 & 0.048 & 88.24 \\
\hline 4 & 26 & 1.2 & 0.9 & 300 & 7 & 0.04 & 0.286 & 66.67 \\
\hline 26 & 27 & 0.75 & 0.6 & 312 & 14 & 0.05 & 1.179 & 69 \\
\hline 20 & 28 & 0.75 & 0.9 & 312 & 14 & 0.04 & 0.143 & 75 \\
\hline 29 & 29 & 0.75 & 0.6 & 312 & 7 & 0.05 & 0.179 & 69 \\
\hline 23 & 30 & 0.75 & 0.6 & 312 & 21 & 0.05 & 0.357 & 58.33 \\
\hline
\end{tabular}

Fig. 7B-D depicts that increasing both time and temperature has a drastic effect on the expected response due to the increase of the environmental conditions, also enhancing the level of inhibitor promotes the inhibition process. It is known that when the average atmospheric temperature conditions are high, tendency of electrochemical reactions to occur is positive. Accordingly, the optimization overlay plot obtained conform with the experimental results, which suggest that bitter kola leaf is a potential plant extract for surface treatment of mild steel in aggressive environments.

\subsection{Analysis of the Inhibition Efficiency, IE (\%) as Determined using RSM}

Mathematical Model of the Corrosion Inhibition Efficiency

Mathematical equations in terms of coded factors can be adopted to evaluate the response for a given levels of each factor, the big levels of the factors are coded as +1 and the small levels of the factors are coded as -1 . The coded equation is vital for identifying the relative effects of the factors by comparing the factor coefficients.

\section{Final Equation in Terms of Coded Factors}

$\mathrm{IE}=+0.18-2.056 \mathrm{E}-003 * \mathrm{~A}-0.082 * \mathrm{~B}+0.067 * \mathrm{C}-0.14$ ${ }^{*} \mathrm{D}-0.015 * \mathrm{AB}-6.250 \mathrm{E}-005 * \mathrm{AC}+8.813 \mathrm{E}-003 * \mathrm{AD}-$ $6.250 \mathrm{E}-005 * \mathrm{BC}+0.015 * \mathrm{BD}-0.012 \mathrm{CD}+0.080 * \mathrm{~A}^{2}+$ $0.027 * B^{2}+85.70 E-003 C^{2}+0.050 * D^{2}$

\section{Final Equations in Terms of Actual Factors}

$\mathrm{IE}=+4.63018-0.56740$ * Acid Conc. -0.63864 * Inhibitor Conc. $-0.029564 *$ Temperature $-0.010642 *$ Time -0.10972 * Acid Conc. * Inhibitor Conc. $-1.15741 \mathrm{E}-005{ }^{*}$ Acid Conc. *Temperature $+2.79762 \mathrm{E}-003 *$ Acid Conc. ${ }^{*}$ Time + 1.73611E $-005 *$ Inhibitor Conc. ${ }^{*}$ Temperature + 7.05357E 003 * Inhibitor Conc. * Time

From Table 9, the F-value of 91.55 was obtained. It demonstrates that the model is significant. There was only a $0.01 \%$ chance that F-value obtained could occur due to noise. The noise may be assigned to flow rates of the heterocyclic compounds present in the inhibitor. Values of Prob > F lower than 0.0500 
(A)

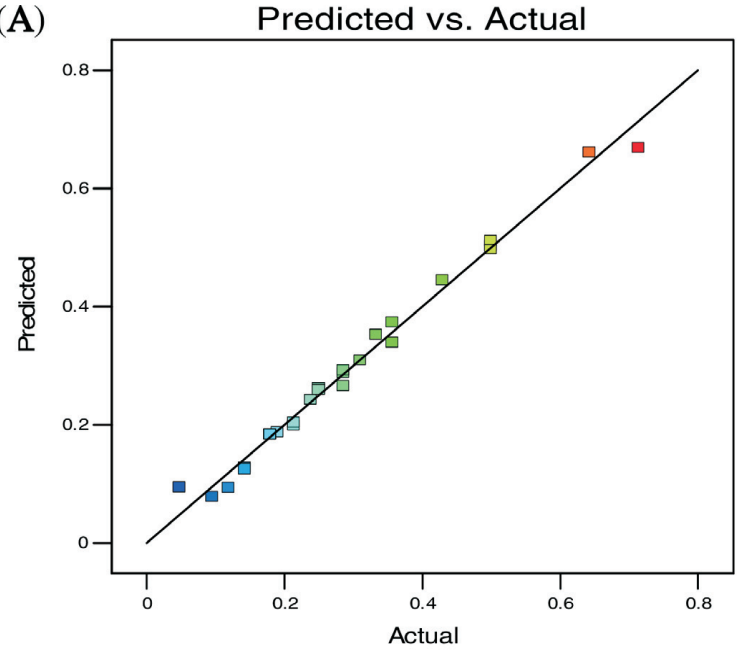

Design-Expert( $)$ Sottware

Color points by value of

Corrosion Rate:

$\prod_{0.048}^{0.714}$

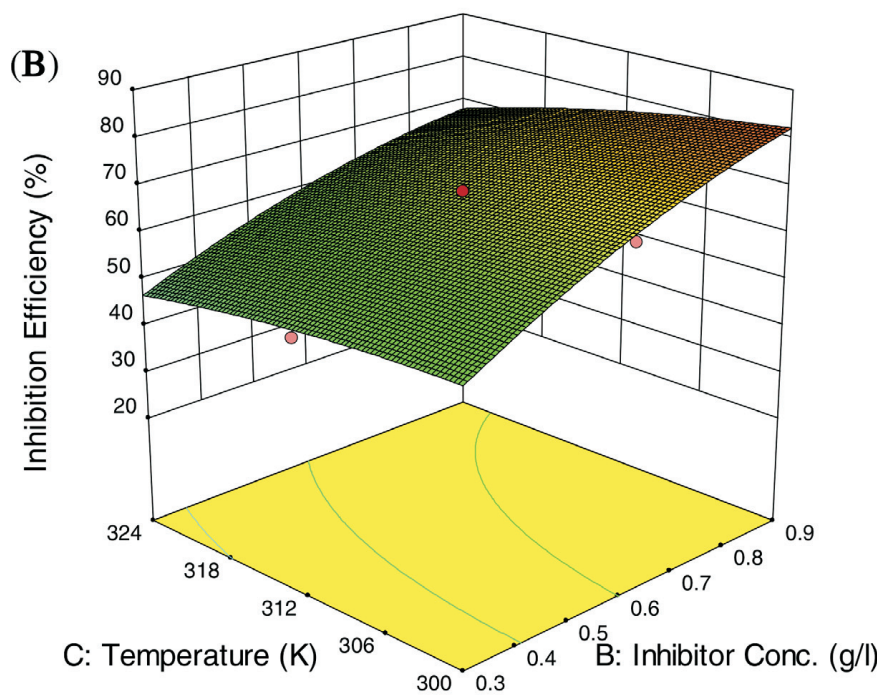

Design-Expert@ Software

Factor Coding: Actual

Inhibition Efficiency (\%)

- Design points above predicted value 88.24

$\bigcup_{25}$
(C)

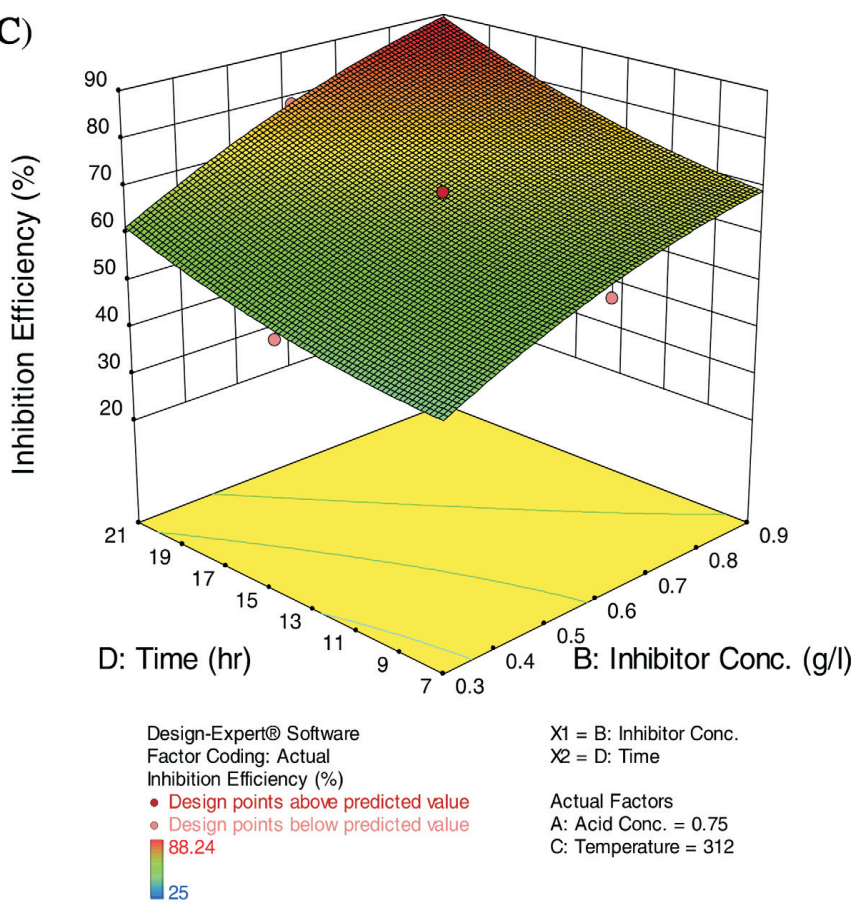

(D)

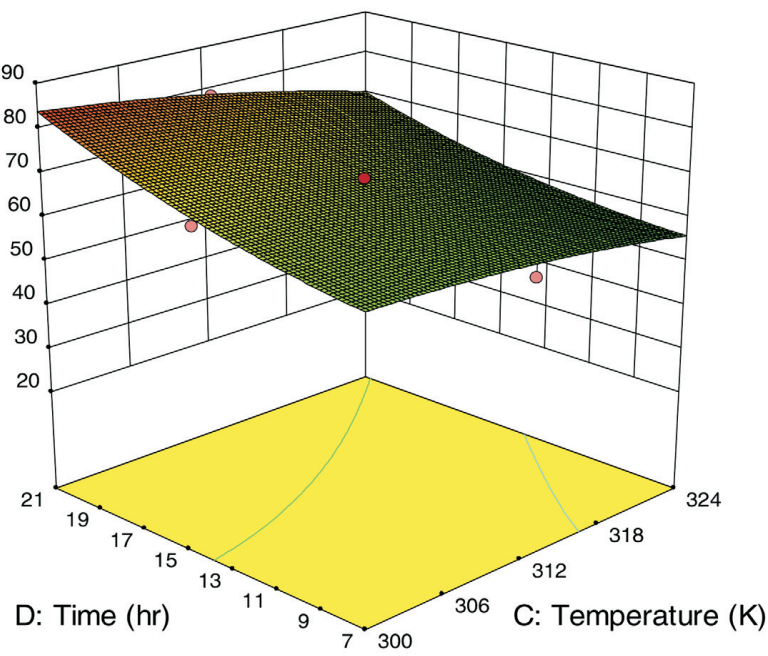

Design-Expert $\circledast$ Software
Factor Coding: Actual

Factor Coding: Actual
Inhibition Efficiency $(\%)$

Inhibition Efficiency (\%)

- Design points below predicted value

28.24

Figure 7 Response surface optimization plots for inhibition efficiency using Design Expert version (10). (a) Predicted versus actual; (b) temperature versus inhibitor concentration; (c) time versus inhibitor concentration; (d) time versus temperature; (e) Overlay plot. (Continued on p. 59.)

shows that model terms are pronounced. Here B, C, D, AB, BD, $A^{\wedge} 2, D^{\wedge} 2$ are pronounced model terms. Values higher than 0.1000 reveal the model terms are not pronounced. From the ANOVA table it was observed that the inhibitor concentration has the highest F-value, followed by time, temperature and acid concentration, respectively. ${ }^{40}$ The coefficient of determination $\mathrm{R}^{2}$ of the model was 0.9884 which prove a good fit between the predicted values and experimental data lines. Furthermore, the $\mathrm{R}^{2}$ explain high dependence and relationship between the observed and predicted values of the response. ${ }^{41}$ Also the 'Pre R-squared' of 0.9159 generated is in line with the Adj R-squared of 0.9776; the difference is lower than 0.2. 'Adeq precision' measures the signal to the noise ratio. A ratio higher than 4 is acceptable. The ratio of 35.019 indicates a good signal.

\subsection{Scanning Electron Microscopy}

The morphological analyses of mild steel are shown in Figs. 8-10). The micrograph of the mild steel revealed that corrosion holes were formed on the surface of the metal due to acid attack which indicates deposition of corrosion particles in the blank solution. Presence of inhibitor altered the rate of corrosion on the surface and a plain layer was noticed which indicates the occurrence of a protective film layer by the active constituents of the extract. This is in agreement with previous research. ${ }^{42-43}$ 

$<$ http://journals.sabinet.co.za/content/journal/chem/>.

Design-Expert $($ Software Factor Coding: Actual Overlay Plot

Inhibition Efficiency - Design Points

$\mathrm{X} 1=\mathrm{A}:$ Acid Conc $\mathrm{X}_{2}=\mathrm{B}$ : Inhibitor Conc.

Actual Factors

C: Temperature $=300$ D: Time $=2$

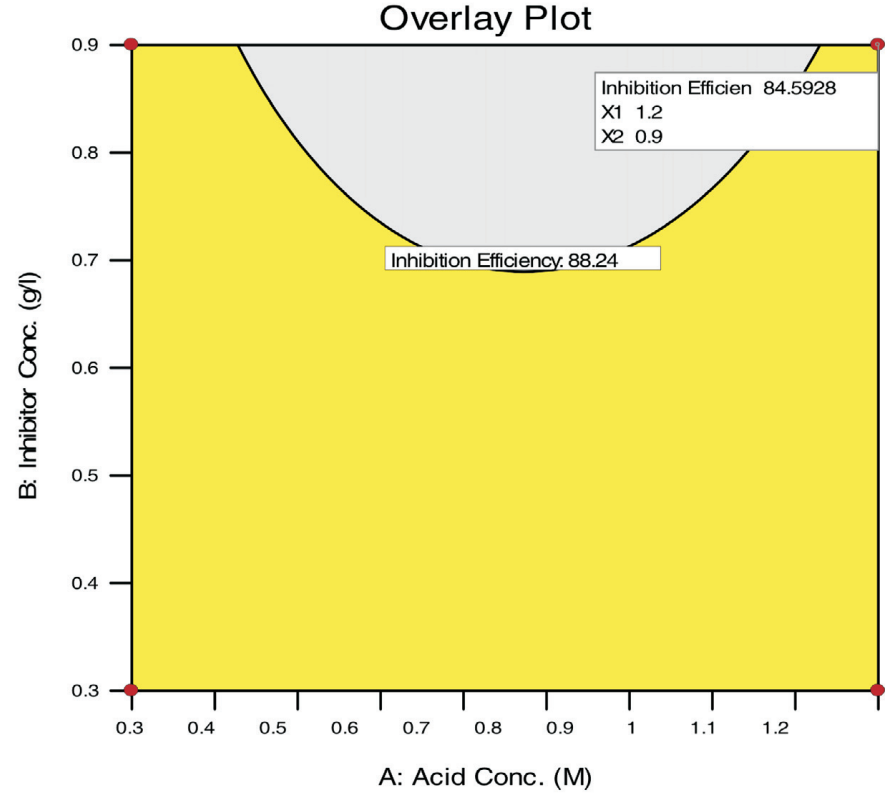

(E)

Figure 7 (continued)

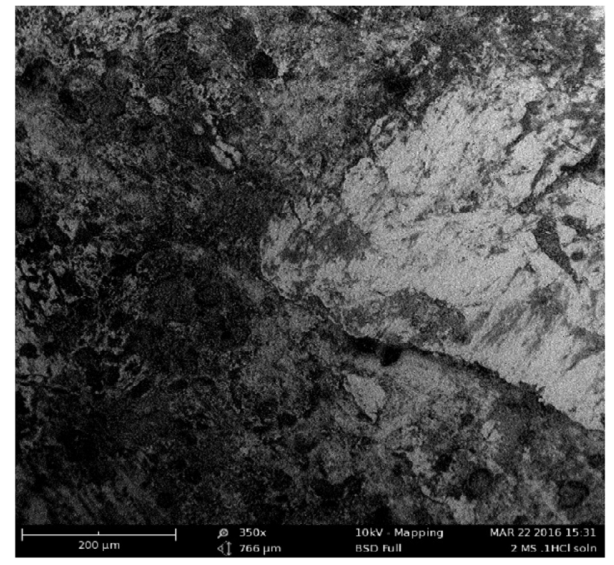

Figure 8 Mild steel in absence of inhibitor.

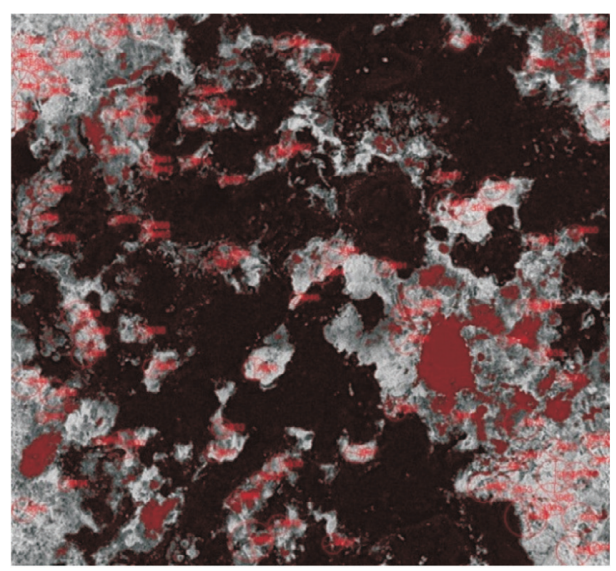

(a)

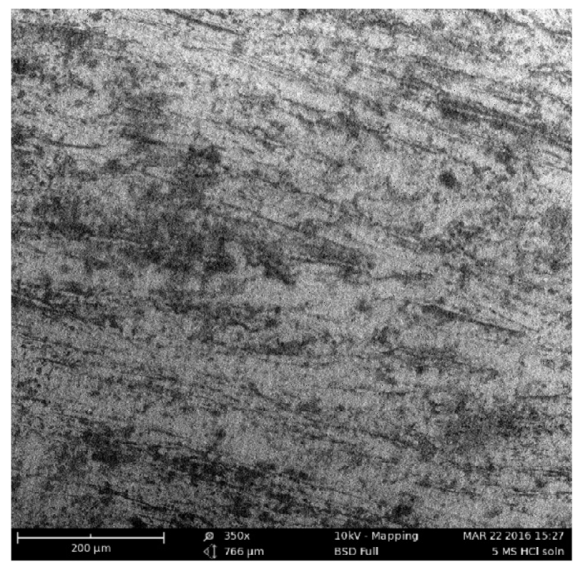

Figure 9 Mild steel in presence of inhibitor.

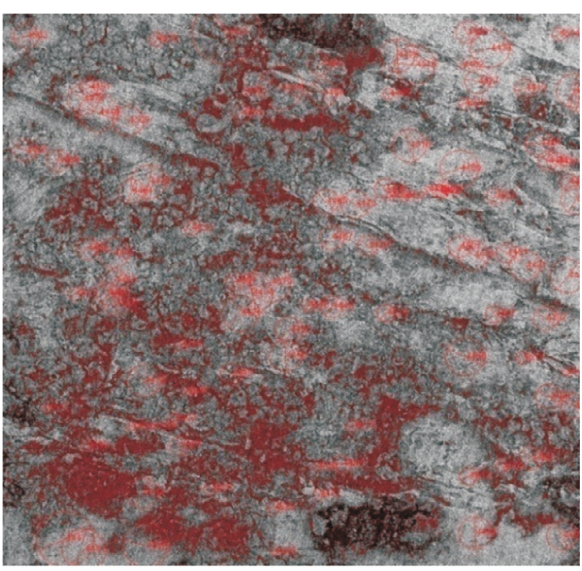

(b)

Figure 10 Fibre metric image of mild steel in the (a) absence and in the (b) presence of inhibitor.

\section{Conclusions}

The obtained results indicate that BKL is a potential extract to be used for surface treatment of mild steel corrosion in $\mathrm{HCl}$ environment. Polarization technique signifies that BKL functioned as a mixed-mode inhibitor, which the impedance data revealed was accomplished through adsorption of BKL molecules on the metal surface. The adsorption of BKL on the metal surface conforms to physical adsorption process. Response surface method- 
Table 9 ANOVA results for response surface Quadratic model.

\begin{tabular}{|c|c|c|c|c|c|c|}
\hline & Sum of squares & d.f. & Mean square & F-value & $\begin{array}{l}\text { P-value } \\
\text { Prob }>\text { F }\end{array}$ & \\
\hline Model & 0.73 & 14 & 0.052 & 91.55 & $<0.0001$ & Significant \\
\hline A-Acid conc. & $7.606 \mathrm{E}$ & 1 & $7.606 \mathrm{E}$ & 0.13 & 0.7195 & \\
\hline B-Inhibitor conc. & 0.12 & 1 & 0.12 & 623.94 & $<0.0001$ & \\
\hline C-Temperature & 0.080 & 1 & 0.080 & 141.39 & $<0.0001$ & \\
\hline D-Time & 0.35 & 1 & 0.35 & 213.20 & $<0.0001$ & \\
\hline $\mathrm{AB}$ & $3.511 \mathrm{E}$ & 1 & $3.511 \mathrm{E}$ & 6.18 & 0.0252 & \\
\hline $\mathrm{AC}$ & $6.250 \mathrm{E}$ & 1 & $6.250 \mathrm{E}$ & $1.101 \mathrm{E}$ & 0.9918 & \\
\hline $\mathrm{AD}$ & $1.243 \mathrm{E}$ & 1 & $1.243 \mathrm{E}$ & 2.19 & 0.1597 & \\
\hline $\mathrm{BC}$ & $6.250 \mathrm{E}$ & 1 & $6.250 \mathrm{E}$ & $1.101 \mathrm{E}$ & 0.9918 & \\
\hline $\mathrm{BD}$ & $3.511 \mathrm{E}$ & 1 & $3.511 \mathrm{E}$ & 6.18 & 0.0252 & \\
\hline$C D$ & $2.280 \mathrm{E}$ & 1 & $2.280 \mathrm{E}$ & 4.02 & 0.0635 & \\
\hline $\mathrm{A}^{2}$ & 0.017 & 1 & 0.017 & 29.26 & $<0.0001$ & \\
\hline $\mathrm{B}^{2}$ & $1.829 \mathrm{E}$ & 1 & $1.829 \mathrm{E}$ & 3.22 & 0.0928 & \\
\hline$C^{2}$ & $1.903 \mathrm{E}$ & 1 & $1.903 \mathrm{E}$ & 0.34 & 0.5712 & \\
\hline $\mathrm{D}^{2}$ & $6.495 \mathrm{E}$ & 1 & $6.495 \mathrm{E}$ & 11.44 & 0.0041 & \\
\hline Residual & $8.515 \mathrm{E}$ & 15 & $5.677 \mathrm{E}$ & & & \\
\hline Lack of fit & $8.515 \mathrm{E}$ & 10 & $8.515 \mathrm{E}$ & & & \\
\hline Pure error & 0.000 & 5 & 0.000 & & & \\
\hline Cor total & 0.74 & 29 & & & & \\
\hline Adj. R-square & 0.9776 & & & & & \\
\hline Pre-R-square & 0.9159 & & & & & \\
\hline
\end{tabular}

ology is the best approach for optimizing the inhibition process also reducing the number of experimental runs. Furthermore, the optical investigation revealed the occurrence of a film layer adsorbed on the metal surface, while FTIR studies revealed the functional groups existing in the adsorbed protective layer.

\section{${ }^{s}$ ORCID iDs}

V.C. Anadebe:

\section{orcid.org/0000-0002-7559-446X}

\section{References}

1 M.S. Al-Otaibi, A.M. Al-Mayouf, M. Khan, A.A. Mousa and S.A. Al-Mazroa., Corrosion inhibition action of some plants extracts on the corrosion of mild steel in acidic media, Arabian. J. Chem., 2012, 1-7.

2 I.B. Obot, N.O. Obi-Egbedi and S.A. Umoren., Antifungal drugs as corrosion inhibitors for aluminum in $0.1 \mathrm{M} \mathrm{HCl}$, Corros. Sci., 2009, 51(8), 1868-1875.

3 O.D. Onukwuli and M. Omotioma., Optimization of the inhibition efficiency of mango extracts as corrosion inhibitor of mild steel in $1.0 \mathrm{M} \mathrm{H}_{2} \mathrm{SO}_{4}$ using RSM, J. Chem. Tech. Metallurgy, 2016, 51(3), 302-314.

4 A. Yildirim and M. Cetin, Synthesis and evaluation of new long alkyl side chain acetamide, isoxazolidine and isoxazoline derivatives as corrosion inhibitors, Corros. Sci., 2008, 50, 155-165.

5 M. Omotioma and O.D. Onukwuli, Corrosion inhibition of mild steel in $1.0 \mathrm{M} \mathrm{HCl}$ with castor oil extract as inhibitor, Int. J. Chem. Sci., 2016a, 14(1) 103-127.

6 M. Omotioma and O.D. Onukwuli, Modeling the corrosion inhibition of mild steel in $\mathrm{HCl}$ medium with the inhibitor of paw-paw leaves extract, Port. Electrochim. Acta, 2016b, 34(4), 287-294.

7 P. Bommersbach, C. Alemany-Dumont, J.P. Millet and B. Normand, Formation and behavior study of an environment-friendly corrosion inhibition by electrochemical methods, Electrochim. Acta., 2005, 51(6), 1076-1084.

8 K. Radojcic, S. Berkovic, J. Kovac, Vorkapic-Furac, Natural honey and black radish juice as tin corrosion inhibitors, Corros. Sci., 2008, 50(5), 1498-1504.

9 P.C. Okafor, M. Ikpi, E.I. Uwah, E.E. Ebenso, U.J. Ekpe and S.A. Umoren, Inhibitory action of Phyllanthus amarus extracts on the corrosion of mild steel in acidic media, Corros. Sci., 2008, 50(8), 2310-23177.

10 M. Salasi, T. Sharabi. E. Roayaei and Aliofkharaei, The electrochemical behavior of environment-friendly inhibitors of silicate and phosphonate in corrosion control of carbon steel in soft water media, Mater. Chem. Phys., 2007, 104, 183-190.
11 E.E. Ebenso and U.J. Ekpe, Kinetic study of corrosion inhibition of mild steel in $\mathrm{H}_{2} \mathrm{SO}_{4}$ using carica papaya leaves extract, West. Afr. J. Bio. App. Chem., 1996, 41, 21-27.

12 M. Abdel-Gaber, B.A. Abd-El-Nabey, I.M. Sidahmed, A.M. El-Zayaday and M. Saa, Inhibitive action of some plants extracts on the corrosion of steel in acidic media, Corros. Sci., 2006, 48, 2765-2779.

13 A.S. Fouda, E.H. Megahed, N. Fouda and N.M. Elbahrawt, Corrosion inhibition of carbon steel in 1.M hydrochloric acid solution by aqueous extract of Thevetia peruviana, J. Bio Tribo Corros., 2016, 2, 1-16.

14 D.I. Udunwa, O.D. Onukwuli and M. Omotioma, Corrosion control of aluminum alloy in $\mathrm{HCl}$ medium using extract of Ocimum gratissium as inhibitor, Der Pharma Chemica, 2017, 9(19) 48-59.

15 S. Aribo, J.O. Sunday, J.I. Leonard, O. Akinlabi and O.F. Davies, Green inhibitors for corrosion protection in acidizing oilfield environment, J. Association. Arab. Uni. Basic Appl. Sci., 2017, 24, 34-38.

16 A.A Khadom, A.F. Hassan, B.M. Abod, Evaluation of environmentally friendly inhibitor for galvanic corrosion of steel-copper couple in petroleum waste water, Process Safety. Env. Protection., 2015, 98, 93-101.

17 E.M. Mabrouk, H. Shorkry, K.M. and Abu Al-Naja, Inhibition of aluminum corrosion in acid solution by mono- and bis-azo naphthy lamine dyes. Part 1, Chem. Met. Alloys, 2011, 4, 98-160.

18 N.O. Eddy, B.I Ita, S.N. Dodo and E.D. Paul, Inhibitive and adsorption properties of ethanol extract of Hisbisais sabdariffa calyx for the corrosion of mild steel in $0.1 \mathrm{M} \mathrm{HCl}$, Green Chem. Lett. Rev., 2012, 5(1), 43-53.

19 N. Nagm, N.G. Kandile, E.A. Badr and M.A. Mohammed, Gravimetric and electrochemical evolution of environmentally friendly nonionic corrosion inhibitors for carbon steel in $1 \mathrm{M} \mathrm{HCl}$, Corros. Sci., 2012, 65, 94-103.

20 J.T. Nwabanne and V.N. Okafor, Inhibition of the corrosion of mild steel in acidic medium by Vernonia amygdalina: adsorption and themodynamic study, J. Emerging Trends Eng. Appl. Sci. (JETEAS)., 2011, 2(4), 619-625.

21 V.C. Anadebe, N.A. Okafor, B.O. Okafor and C.C. Emmanuel, Spectroscopic analysis of Garcina kola leaf extract, World News Nat. Sci., $2017,15,162-168$.

22 A.C. Maduabuchi, S. Nwanonenyi, D. Njoku, B.I. Nkem, E.E. Oguzie and Li. Ying, Experimental study on the inhibitive effect of phytic acid as a corrosion inhibitor for Q235 mild steel in $1 \mathrm{M} \mathrm{HCl}$ environment, World News Nat. Sci., 2017, 15, 1-19.

23 M. Abulwahab, A. Kasim, K.A. Bello and J.O. Gaminana, Corrosion inhibition of multi component aluminum alloy in $\mathrm{HCl}$ acid solution by aqueous extract of bitter leaf (Vermina amygdalina) powder. Adv. Mater. Res., 2012, 367, 319-325. 
24 A.A. Khadom, N.A. Ahmed and A.A. Nagham, Xanthium strumarium leaves extracts as a friendly corrosion inhibitor of low carbon steel in HCl: kinetics and mathematical studies, S. Afr. J. Chem. Eng., 2017, 25, 13-21.

25 A.K. Satapathy, G. Gunasekaran, Kumar Amit and P.V. Rodrigues, Corrosion inhibition by justice gendarussa plant extract in hydrochloric acid solution, Corros. Sci., 2009, 51, 1317-1325.

26 L.A Nnanna, I.O. Owate, O.C. Nwadiuko, N.D. Ekekwe and W.J. Oji, Adsorption and corrosion inhibition of gentum Aficana leaves extract on carbon steel. Int. J. Mater. Chem., 2103, 3(1), 10-16.

27 V.G. Vasudha and P.K. Shanmuga, Polyalthia longitolia as a corrosion inhibitor for mild steel in $\mathrm{HCl}$ solution, Res. J. Chem. Sci., 2013, 3(1), 21-26.

28 E.E. Oguzie, Z.O. Ihebunike, K.L Oguzie, C.E. Ogukwe, M.A Chidiebere, C. Enenebeaku and C.O Akaelzi, Corrosion inhibiting effect of Aframomum melegueta extracts and adsorption characteristics of the active constituents on mild steel in acidic media, J. Disp. Sci. Tech. $2013,34,516-527$.

29 M.A. Chidebere, L. Nnanna, A.C. Blessing, K. Oguzie, O. Beluonwu, O. Benedict and E.E. Oguzie, Inhibition of acid corrosion of mild steel using Deonix regia leaves extract, Int. Lett. Chem. Phys. Astron., 2016, 69, $74-86$.

30 E.E. Oguzie, C.K. Enenebeaku, C.O Akalezi, S.C. Okoro, A.A. Ayuk and E.N. Ejike, Adsorption and corrosion inhibiting effect of Dacryodis edulis extract on low carbon steel corrosion in acidic media, J. Colloid. Int. Sci., 2010, 349, 283-292.

31 A. Popova, E. Sokolova, S. Raicheva and M. Christov, AC and DC study of the temperature effect on mild steel corrosion in acid media in the presence of benzimidazole derivatives, Corros. Sci., 2003, 45, $33-58$.

32 H. Ashassi-Sorkhabi, D. Seifzadeh and M.G Hosseini, EN, EIS and polarization studies to evaluate the inhibition effect of $3 \mathrm{H}-$ phenothiazi in -3-one, 7-dimethylamin on mild steel corrosion in $1 \mathrm{M} \mathrm{HCl}$ solution, Corros. Sci., 2008, 50, 3363-3370.
33 F.S. De Souza and A. Spinelli, Caffeic acid as a green corrosion inhibitor for mild steel, Corros. Sci., 2009, 51, 642-649.

34 L.G. Da Trindade and R.S. Goncalves, Evidence of caffeine adsorption on low carbon steel surface in ethanol, Corros. Sci., 2009, 51, 1543-1578.

35 J.C. Da Rocha, Da. Cunha Poniciano Gomes and E. D’Elia, Corrosion inhibition of carbon steel in $\mathrm{HCl}$ solution by fruit peel aqueous extract, Corros. Sci., 2010, 52, 2341-2348.

36 M. Lebrini, F. Robert, A. Lecante and C. Roos, Corrosion inhibition of $\mathrm{C} 38$ steel in $\mathrm{IM} \mathrm{HCl}$ acid medium by alkaloids extract from Oxandra asbecki plant, Corros. Sci., 2010, 53, (2) 687-695.

37 M.A. Chidiebere, E.E. Oguzie, L. Liu, Y. Li and F. Wang, Corrosion inhibition of Q235 mild steel in $0.5 \mathrm{M} \mathrm{H}_{2} \mathrm{SO}_{4}$ solution by phytic acid and synergistic iodide additives, Ind. Eng. Chem. Res., 2014, 53, 7670-7679.

38 M.A. Chidiebere, C.E. Ogukwe, K.L. Oguzie, C.N. Eneh and E.E. Oguzie, Corrosion inhibition and adsorption behavior of Punica granatum extract on mild steel in acidic environments: experimental and theoretical studies, Ind. Eng. Chem. Res., 2012, 51, 668-677.

39 M.A. Chidiebere, E.E. Oguzie, L. Liu, L. Ying and F. Wang, Adsorption and corrosion inhibiting effect of riboflavin on Q235 mild steel corrosion in acidic environments, Mater. Chem. Phys., 2015, 156, 95-104.

40 D. Bas and I.H. Bayaci, Modeling and optimization I: usability of response surface methodology, J. Food. Eng., 2007, 78, 836-845.

41 P. Sharma, L. Singh and N. Dilbaghi, Optimization of green variables for decolorization of disperse yellow 211 by Bascillus subtiles using Box-Behnken design, J. Hazard. Mater., 2009, 164, 1024-1029.

42 K.K. Alaneme, Y.S. Daramola, S.J. Olusegun and A.S Afolabi, Corrosion inhibition and adsorption characteristics of rice husk extracts on mild steel immersed in $1 \mathrm{M} \mathrm{H}_{2} \mathrm{SO}_{4}$ and $\mathrm{HCl}$ solutions. Int. J. Electrochem. Sci., 2015, 50, 3553-3567.

43 K.H. Hassan, A.A. Khadom and N.H. Kurshed, Citrus aurantium leaves extract as a sustainable corrosion inhibitor of mild steel in sulfuric acid. S. Afr. J. Chem. Eng., 2016, 22, 1-5. 